\title{
Protective effect of L-carnitine on myocardial injury in rats with heatstroke ${ }^{1}$
}

\author{
Xisong Wang' (iD, Yingyu Liu" (iD, Chunlai Zhang"II (iD, Qing Song ${ }^{\text {IV }}$ (D)
}

' PhD, Department of Critical Care Medicine, Chinese People's Liberation Army General Hospital, People's Liberation Army Medical College, Beijing, China. Design the study, critical revision, final approval.

"Master, Department of Respiratory Medicine, Tangshan Central Hospital, Tangshan, China. Technical procedures, critical revision, final approval.

I"'Master, Department of Cardiology, Tangshan Central Hospital, Tangshan, China. Acquisition of data, statistical analysis, critical revision, final approval.

"Master, Department of Critical Care Medicine, Chinese People's Liberation Army General Hospital, People's Liberation Army Medical College, Beijing, China. Design the study, critical revision, final approval.

\begin{abstract}
Purpose: To investigate the protective effect of L-carnitine on myocardial injury in rats with heatstroke.

Methods: Forty-eight rats were randomly divided into control, heatstroke and 25, 50 and $100 \mathrm{mg} / \mathrm{kg}$ L-carnitine groups. The last three groups were treated with 25,50 and $100 \mathrm{mg} / \mathrm{kg} \mathrm{L}$-carnitine, respectively, for seven successive days. Then, except for the control group, the other four groups were transferred into the environment with ambient temperature of $\left(39.5 \pm 0.4{ }^{\circ} \mathrm{C}\right)$ and relative humidity of $(13.5 \pm 2.1 \%)$ for $2 \mathrm{~h}$. The core temperature (Tc), mean arterial pressure (MAP), heart rate (HR) and serum and myocardial indexes were detected.

Results: Compared with the heatstroke group, in the $100 \mathrm{mg} / \mathrm{kg}$ L-carnitine group, the Tc was significantly decreased, the MAP and HR were significantly increased, the serum creatine kinase, lactate dehydrogenase, alkaline phosphatase, aspartate aminotransferase, tumor necrosis factor $\alpha$ and interleukin $1 \beta$ levels were significantly decreased, the myocardial superoxide dismutase and glutathione peroxidase levels were significantly increased, the myocardial malondialdehyde level was significantly decreased and the cardiomyocyte apoptosis index and myocardial caspase-3 protein expression level were remarkably decreased $(p<0.05)$.
\end{abstract}

Conclusion: The L-carnitine pretreatment can alleviate the myocardial injury in heatstroke rats through reducing the inflammatory response, oxidative stress and cardiomyocyte apoptosis.

Key words: Carnitine. Heatstroke. Myocardial Reperfusion Injury. Rats. 


\section{- Introduction}

Heatstroke is a serious manifestation of heat injury and a serious life-threatening disease. Clinically, it is defined as the core temperature $\left(T_{c}\right)$ being over $40{ }^{\circ} \mathrm{C}$, body temperature regulation failure and central nervous system symptoms, such as convulsion, coma, delirium and others ${ }^{1,2}$. With the global warming, the incidence of heatstrokes is increasing year by year. The heatstroke can cause the systemic inflammatory response, which leads to multiple organ dysfunction or failure, including hemorrhage and necrosis in the brain, lung, heart, gastrointestinal tract and kidney $^{2}$. It is reported that the heat stress can induce the cardiomyocyte apoptosis and heart dysfunction ${ }^{3}$. L-carnitine is a compound with multiple physiological functions, which mainly exists in the heart and skeletal muscle of the body ${ }^{4}$. On one hand, as the carrier of fatty acid transportation, L-carnitine can transfer the medium and long-chain fatty acids from the outside of cell mitochondrial membrane to the inside of membrane, which are then oxidized in the mitochondrial matrix for generating energy 5 . On the other hand, L-carnitine is an antioxidant with the function of scavenging free radicals. It can capture the free radicals and promote the reacylation of membrane phospholipids, which is conducive to the repair of biofilm and resistance of oxidation ${ }^{6,7}$. In this study, the heatstroke model of rats was established, and the protective effect and mechanism of L-carnitine on myocardial injury in rats with heatstroke were investigated.

\section{- Methods}

This study was performed with the approval of the ethics committee of Chinese PLA General Hospital, PLA Medical College. All animal procedures followed the Guide for the Care and Use of Laboratory Animals by the National Institutes of Health.

Forty-eight male Sprague-Dawley rats (220-250 g) were adaptively fed in normal condition for seven days. Then, the rats were randomly divided into control group, heatstroke group and 25, 50 and $100 \mathrm{mg} / \mathrm{kg}$ L-carnitine groups, with 8 rats in each group. The last three groups were treated with 25,50 and $100 \mathrm{mg} / \mathrm{kg}$ L-carnitine by intraperitoneal injection, respectively. The treatment was conducted once per day, for seven successive days. The control and heatstroke groups were synchronously given with same volume of normal saline.

\section{Modeling of heatstroke}

On the eighth day of the experiment, except for the control group, the other four groups were transferred to the artificial climate chamber with ambient temperature of $\left(39.2 \pm 0.4^{\circ} \mathrm{C}\right)$ and relative humidity of $(13.5 \pm 2.1 \%)$, with water deprivation and fasting. The modeling was performed for $2 \mathrm{~h}$. During the modeling, no rat died in any group.

\section{Measurement of $T_{c^{\prime}}$ mean arterial pressure and heart rate of rats}

After $2 \mathrm{~h}$ of modeling, the rats were anesthetized. The femoral artery was separated, followed by intubation and connection to the multichannel physiological recorder through pressure transducer. The $T_{c^{\prime}}$ mean arterial pressure (MAP) and heart rate (HR) were measured.

\section{Detection of serum indexes}

The rats were anesthetized by intraperitoneal injection of $3 \%$ sodium pentobarbital and then were executed by decapitation. The vena cava blood was taken. After centrifuged at $3000 \mathrm{rpm}$ and $4{ }^{\circ} \mathrm{C}$ for 15 min, the serum was obtained. The serum creatine kinase (CK), lactate dehydrogenase (LDH), alkaline phosphatase (ALP) and aspartate aminotransferase (AST) levels were detected by automatic biochemical detector. The serum tumor necrosis factor $\alpha$ (TNF- $\alpha$ ) and interleukin $1 \beta$ (IL-1 $\beta$ ) were detected by enzyme linked immunosorbent assay.

\section{Determination of myocardial oxidative stress indexes}

The heart tissue of rats was taken and homogenized with normal saline under the condition of ice bath. After centrifuged at $3000 \mathrm{rpm}$ and $4{ }^{\circ} \mathrm{C}$ for $15 \mathrm{~min}$, the supernatant was obtained. The levels of superoxide dismutase (SOD), glutathione peroxidase (GSH-Px) and malondialdehyde (MDA) were determination by ultravioletvisible spectrophotometry.

\section{Determination of cardiomyocyte apoptosis indexes}

The heart tissue of rats was taken. The cardiomyocyte apoptosis was determined using the TUNEL method and the apoptotic index (percentage of apoptotic cells in total cells) was calculated ${ }^{8}$. In addition, the expression level of Caspase- 3 protein in myocardial tissue was determined by western blotting ${ }^{9}$. The determination procedures were according to the instructions of kits.

\section{Statistical analysis}

Group data were presented as mean \pm standard deviation. The differences among the experimental groups were examined using one-way analysis of variance (ANOVA) with post-hoc Tukey test. $\mathrm{P}<0.05$ was considered statistically significant. 


\section{Results}

\section{Effect of L-carnitine on $T_{c}$ MAP and HR in thermal injury rats}

After $2 \mathrm{~h}$ of heatstroke modeling, in the heatstroke group, the $T_{c}$ significantly increased $(p<0.05)$, and the MAP and HR significantly decreased, $(p<0.05)$ compared with the control group. Compared with heatstroke group, the $\mathrm{T}_{c}$ in 25 , 50 and $100 \mathrm{mg} / \mathrm{kg} \mathrm{L}$-carnitine groups significantly decreased $(p<0.05)$ and the MAP in 50 and $100 \mathrm{mg} / \mathrm{kg}$ L-carnitine groups and $\mathrm{HR}$ in 25,50 and $100 \mathrm{mg} / \mathrm{kg}$ L-carnitine groups significantly increased $(p<0.05)$ (Fig. 1).
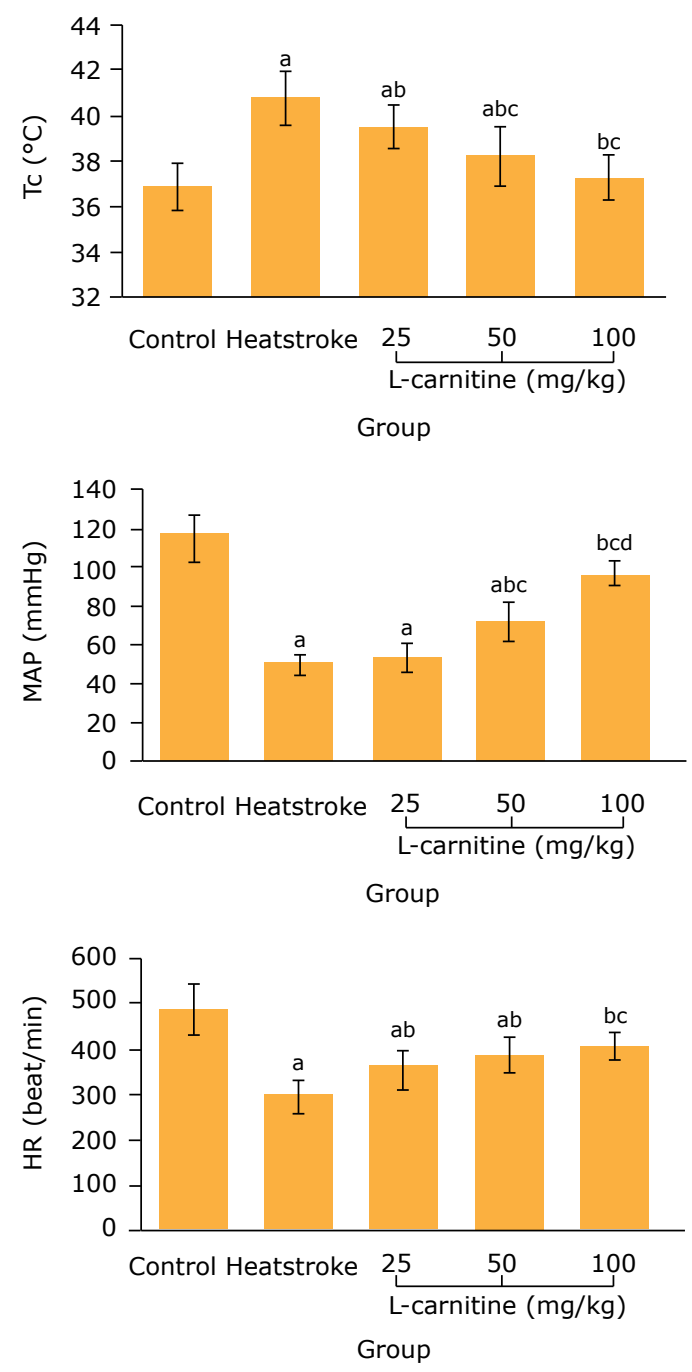

Figure 1 - Comparison of $\mathrm{T}_{\mathrm{c}^{\prime}}$ map and $\mathrm{hr}$ among five groups $(\mathrm{n}=8)$. ${ }^{\mathrm{a}} \mathrm{P}<0.05$ vs. control group; ${ }^{\mathrm{b} P}<0.05$ vs. heatstroke group; ${ }^{\mathrm{C} P}<0.05$ vs. $25 \mathrm{mg} / \mathrm{kg}$ L-carnitine group; ${ }^{\mathrm{d}} \mathrm{P}<0.05$ vs. $50 \mathrm{mg} / \mathrm{kg}$ L-carnitine group. $\mathrm{T}_{c}$ : core temperature; MAP: mean arterial pressure; HR: heart rate.

\section{Effect of L-carnitine on serum CK, $L D H, A L P$ and AST levels in thermal injury rats}

As shown in Fig. 2, after $2 \mathrm{~h}$ of heatstroke modeling, the serum CK, LDH, ALP and AST levels in heatstroke group were significantly higher than those in the control group $(p<0.05)$.
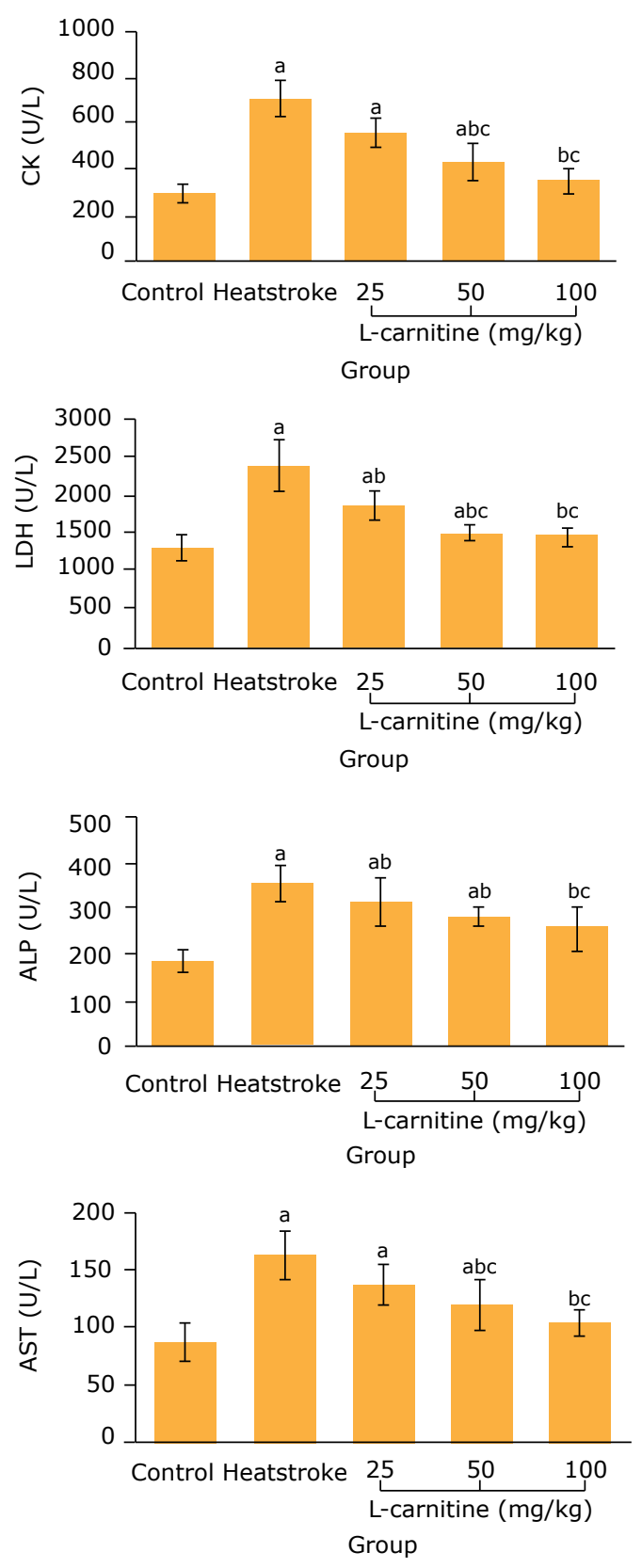

Figure 2 - Comparison of serum CK, LDH, ALP and AST levels among five groups $(n=8)$. aP $<0.05$ vs. control group; ${ }^{\mathrm{b} P}<0.05$ vs. heatstroke group; ${ }^{\mathrm{c} P}<0.05$ vs. $25 \mathrm{mg} / \mathrm{kg}$ $\mathrm{L}$-carnitine group; ${ }^{\mathrm{d}} \mathrm{P}<0.05 \mathrm{vs} .50 \mathrm{mg} / \mathrm{kg} \mathrm{L}$-carnitine group. CK: creatine kinase; LDH: lactate dehydrogenase; ALP: alkaline phosphatase; AST: aspartate aminotransferase. 
Compared with the heatstroke group, the serum CK and AST levels in 50 and $100 \mathrm{mg} / \mathrm{kg}$ L-carnitine groups and the serum $\mathrm{LDH}$ and ALP levels in 25, 50 and $100 \mathrm{mg} / \mathrm{kg}$ L-carnitine groups significantly decreased $(p<0.05)$.

\section{Effect of L-carnitine on serum TNF- $\alpha$ and IL-16 levels in thermal injury rats}

Figure 3 showed that, compared with the control group, the serum TNF- $\alpha$ and IL-1 $\beta$ levels in the heatstroke group were remarkably increased $(p<0.05)$. Compared with the heatstroke group, the serum TNF- $\alpha$ level in 50 and $100 \mathrm{mg} / \mathrm{kg} \mathrm{L-carnitine} \mathrm{groups} \mathrm{and} \mathrm{the} \mathrm{IL-1 \beta} \mathrm{level} \mathrm{in}$ 25,50 and $100 \mathrm{mg} / \mathrm{kg}$ L-carnitine groups were remarkably decreased $(P<0.05)$.
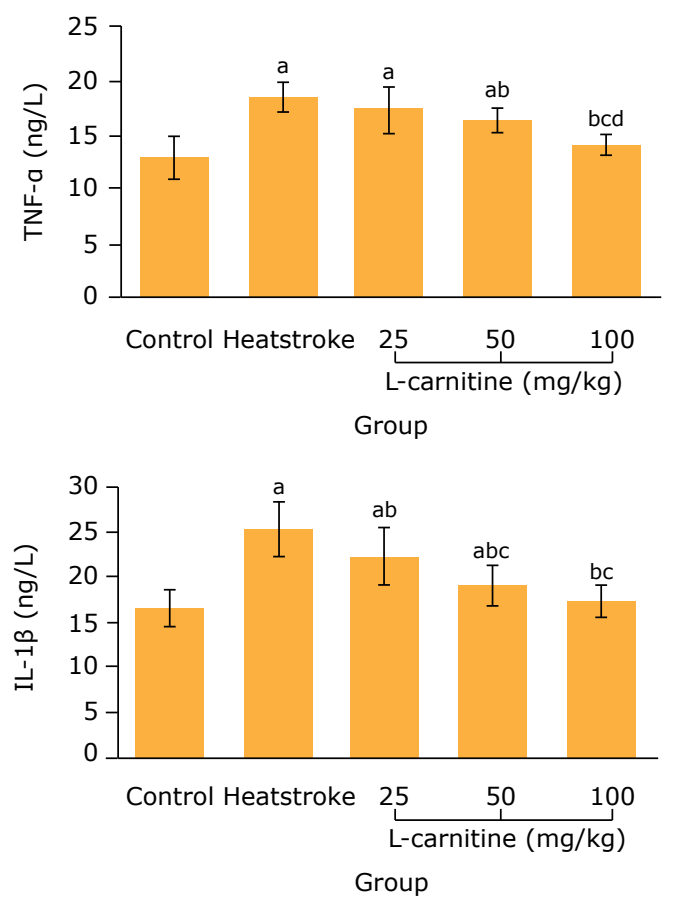

Figure 3 - Comparison of serum TNF- $\alpha$ and IL-1 $\beta$ levels among five groups $(n=8)$. ${ }^{\text {a }}<0.05$ vs. control group; ${ }^{\text {bP }}<0.05$ vs. heatstroke group; ${ }^{\mathrm{P}}<0.05$ vs. $25 \mathrm{mg} / \mathrm{kg}$ L-carnitine group; ${ }^{\mathrm{d}} \mathrm{P}<0.05$ vs. $50 \mathrm{mg} / \mathrm{kg}$ L-carnitine group. TNF- $\alpha$ : tumor necrosis factor $\alpha$; IL-1 $\beta$ : interleukin $1 \beta$.

\section{Effect of L-carnitine on myocardial SOD, GSH-Px and MDA levels in thermal injury rats}

After $2 \mathrm{~h}$ of heatstroke modeling, the myocardial SOD and GSH-Px levels in the heatstroke group significantly decreased, compared with the control group ( $<<0.05)$, and the myocardial MDA level significantly increased $(p<0.05)$. Compared with the heatstroke group, the myocardial SOD level in 50 and $100 \mathrm{mg} / \mathrm{kg}$ L-carnitine groups and GSH-Px level in $100 \mathrm{mg} / \mathrm{kg}$ L-carnitine group significantly increased ( $p<0.05)$, and the myocardial MDA level in 25, 50 and $100 \mathrm{mg} / \mathrm{kg}$ L-carnitine groups significantly decreased ( $p<0.05$ ) (Fig. 4).
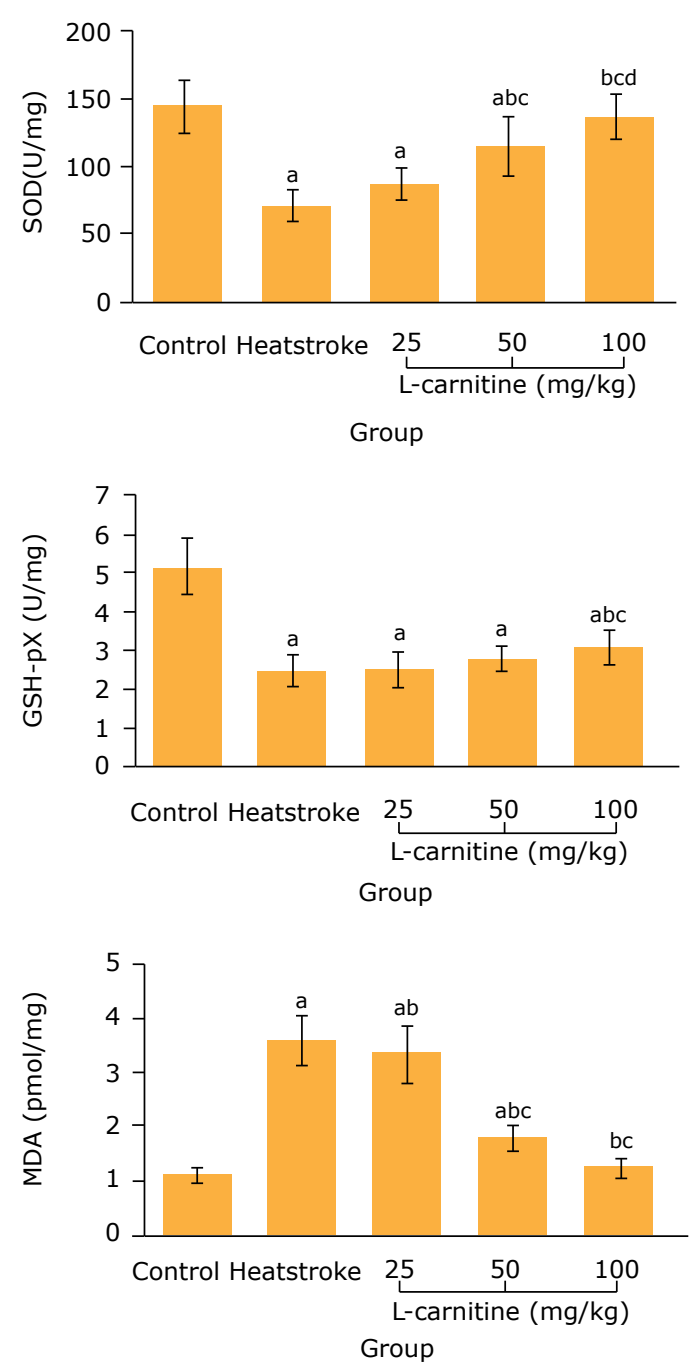

Figure 4 - Comparison of myocardial SOD, GSH-Px and MDA levels among five groups $(n=8)$. ${ }^{\mathrm{a}} \mathrm{P}<0.05 \mathrm{vs}$. control group; ${ }^{\text {b }}<0.05$ vs. heatstroke group; ${ }^{~} \mathrm{P}<0.05$ vs. $25 \mathrm{mg} /$ $\mathrm{kg} \mathrm{L-carnitine} \mathrm{group;}{ }^{\mathrm{d}} \mathrm{P}<0.05$ vs. $50 \mathrm{mg} / \mathrm{kg}$ L-carnitine group. SOD: superoxide dismutase; GSH-Px: glutathione peroxidase; MDA: malondialdehyde.

\section{Effect of L-carnitine on cardiomyocyte apoptosis} index and myocardial caspase-3 protein expression in thermal injury rats

Compared with the control group, the cardiomyocyte apoptosis index and myocardial caspase-3 protein expression 
levels in the heatstroke group were remarkably increased $(p<0.05)$. Compared with the heatstroke group, the cardiomyocyte apoptosis index in 25, 50 and $100 \mathrm{mg} / \mathrm{kg}$ $\mathrm{L}$-carnitine groups and the myocardial caspase- 3 protein expression level in 50 and $100 \mathrm{mg} / \mathrm{kg}$ L-carnitine groups were remarkably decreased ( $p<0.05$ ) (Fig. 5).
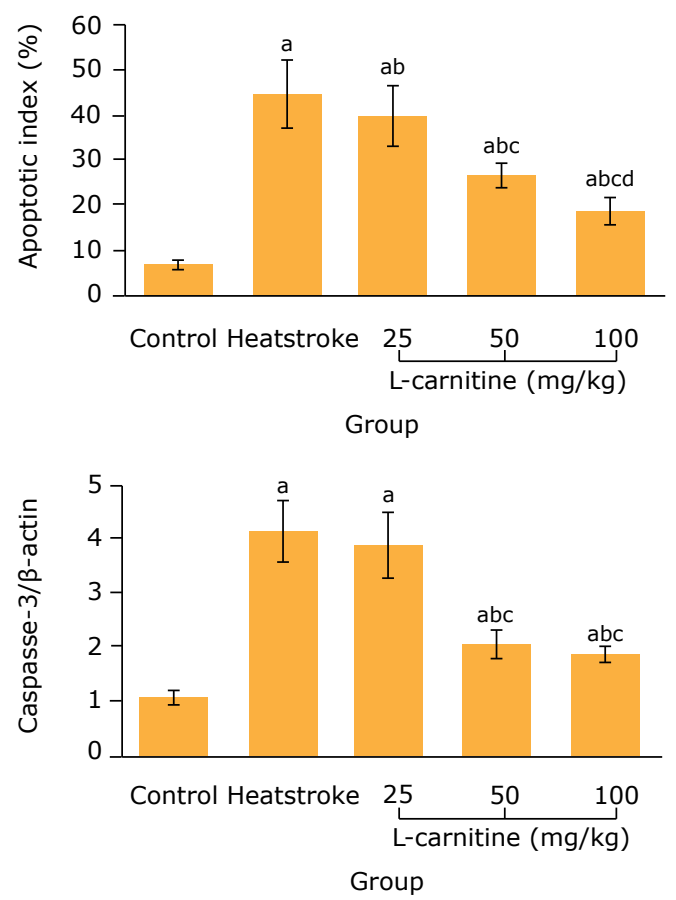

Figure $\mathbf{5}$ - Comparison of cardiomyocyte apoptosis index and myocardial caspase-3 protein expression among five groups $(n=8)$. a $P<0.05$ vs. control group; ${ }^{\text {b }}<0.05$ vs. heatstroke group; ${ }^{\mathrm{C} P}<0.05$ vs. $25 \mathrm{mg} / \mathrm{kg}$ L-carnitine group; ${ }^{\mathrm{d}} \mathrm{P}<0.05$ vs. $50 \mathrm{mg} / \mathrm{kg}$ L-carnitine group.

\section{- Discussion}

This study has established the heatstroke model of rats and investigated the protective effect of L-carnitine on myocardial injury in heatstroke rats. The changes of $T_{c^{\prime}}$ MAP and HR are the important indications of heatstroke. Results of this study showed that, after $2 \mathrm{~h}$ of modeling, the $\mathrm{T}_{c}$ significantly decreased and the MAP and HR significantly increased in 50 and $100 \mathrm{mg} / \mathrm{kg}$ L-carnitine groups, when compared with the heatstroke group. This indicates that the L-carnitine pretreatment can lighten the symptoms of heatstroke in rats. Creatine kinase, LDH, ALP and AST widely exist in the cytoplasm and mitochondria of tissue cells of myocardium and skeletal muscle. When the myocardium is damaged, the levels of these enzymes show different degrees of elevation. They are released into the blood in large quantities. Therefore, the serum CK, LDH, ALP and
AST levels can reflect the degree of myocardial injury ${ }^{10,11}$. Results of this study showed that the serum CK, LDH, ALP and AST levels in 50 and $100 \mathrm{mg} / \mathrm{kg}$ L-carnitine groups significantly decreased compared with the heatstroke group. This suggests that the L-carnitine pretreatment can alleviate the myocardial injury in heatstroke rats.

Heatstroke can cause the systemic inflammatory response syndrome ${ }^{12}$. The cytokines, such as TNF- $\alpha$ and $\mathrm{IL}-1 \beta$, are closely related to the occurrence and development of systemic inflammatory response syndrome. Tumor necrosis factor $\alpha$ is a key factor in inflammatory response and plays an important role in neutrophil recruitment and inflammatory cascade reaction. In addition, TNF- $\alpha$ can induce the production of other inflammatory cytokines, such as IL-1 $\beta$ and IL-6, which can also stimulate the migration and adhesion of neutrophils and induce the inflammatory cascade reaction, thus leading to the tissue damage ${ }^{13}$. The increased serum TNF- $\alpha$ and IL-1 $\beta$ levels are closely related to the myocardial injury ${ }^{14}$. In the present study, the serum TNF- $\alpha$ and IL-1 $\beta$ levels in 50 and $100 \mathrm{mg} / \mathrm{kg}$ $\mathrm{L}$-carnitine groups were remarkably decreased compared with heatstroke group. This suggests that, the L-carnitine pretreatment can reduce the inflammatory response, which may be related to its alleviation of myocardial injury in heatstroke rats.

Oxidative stress of cells can cause the release of toxic free radicals from endothelial cells and vascular smooth muscle cells. It is found that the oxidative stress plays an important role in the pathogenesis of cardiovascular disease, including atherosclerosis, hypertension, vascular endothelial dysfunction and ischemic heart disease ${ }^{15}$. Superoxide dismutase and GSH-Px are the main antioxidant enzymes in the body. Malondialdehyde is the product of lipid peroxidation. Therefore, the myocardial SOD, GSH-Px and MDA levels can be used as indirect indicators of myocardial oxidative stress injury ${ }^{16}$. Results of this study showed that the myocardial SOD and GSH-Px levels were significantly increased and the myocardial MDA level was significantly decreased in the $100 \mathrm{mg} / \mathrm{kg}$ L-carnitine group, when compared with the heatstroke group. It can be concluded that, the L-carnitine can resist the myocardial oxidative stress, thus alleviating the myocardial injury in heatstroke rats.

Apoptosis is a process of programmed active death of cells under certain physiological or pathological conditions for maintaining the stability of their internal environment. Heatstroke is often manifested as systemic inflammatory response syndrome or sepsis. In heatstroke, the increase of inflammatory cytokines in body leads to the aggregation of neutrophils and other leukocytes, which release toxins to induce the cell apoptosis ${ }^{17}$. Caspases are the promoters and executors of apoptosis in mammalian cells ${ }^{18}$. Caspase- 3 is 
the most important apoptotic protease in the downstream of Caspases cascade. It is also a marker enzyme of cell apoptosis ${ }^{19}$. In this study, the cardiomyocyte apoptosis index and myocardial caspase-3 protein expression level were remarkably decreased in the 50 and $100 \mathrm{mg} / \mathrm{kg} \mathrm{L-carnitine} \mathrm{groups,} \mathrm{compared} \mathrm{with} \mathrm{the}$ heatstroke group. This indicates that, L-carnitine can reduce the cardiomyocyte apoptosis, which contributes to the alleviation of myocardial injury in heatstroke rats.

\section{- Conclusions}

It has been firstly demonstrated that the L-carnitine pretreatment can alleviate the myocardial injury in heatstroke rats through reducing inflammatory response, oxidative stress and cardiomyocyte apoptosis. This study has some limitations. Firstly, the heatstroke can cause the systemic inflammatory response syndrome. The changes of serum CK, LDH, ALP and AST levels are not the specific markers of myocardial injury. They may be affected by the injury of other organs. Therefore, in a next study, the changes of serum CK, LDH, ALP and AST levels to reflect the myocardial injury should be further investigated under the condition that other organs are also affected by heatstroke. Secondly, there may be other mechanisms for the protective effect of L-carnitine on myocardial injury in heatstroke, which needs to be confirmed by more studies.

\section{- References}

1. Glazer JL. Management of heatstroke and heat exhaustion. Am Fam Physician. 2005;71(11):2133-40. https://doi. org/10.1056/NEJM200506023522220

2. Eshel GM, Safar P. The role of the central nervous system in heatstroke: reversible profound depression of cerebral activity in a primate model. Aviat Space Environ Med. 2002;73(4):327-32; discussion 333-4.

3. Liu Z-F, Ji J-J, Zheng D, Su L, Peng T. Calpain-2 protects against heat stress-induced cardiomyocyte apoptosis and heart dysfunction by blocking p38 mitogen-activated protein kinase activation. J Cell Physiol. 2019;234(7):10761-70. https://doi.org/10.1002/jcp.27750

4. Vescovo G, Ravara B, Gobbo V, Sandri M, Angelini A, Barbera $M D$, et al. L-Carnitine: a potential treatment for blocking apoptosis and preventing skeletal muscle myopathy in heart failure. Am J Physiol Cell Physiol. 2002;283(3):C80210. https://doi.org/10.1152/ajpcell.00046.2002

5. Panchal SK, Poudyal H, Ward LC, Waanders J, Brown L. Modulation of tissue fatty acids by L-carnitine attenuates metabolic syndrome in diet-induced obese rats. Food Funct. 2015;6(8):2496-506. https://doi.org/10.1039/c5fo00480b

6. Arduini A, Gorbunov N, Arrigoni-Martelli E, Dottori S, Molajoni F, Russo F, et al. Effects of L-carnitine and its acetate and propionate esters on the molecular dynamics of human erythrocyte membrane. Biochim Biophys Acta. 1993;1146(2):229-35. https://doi.org/10.1016/00052736(93)90360-C
7. Kalaiselvi T, Panneerselvam C. Effect of L-carnitine on the status of lipid peroxidation and antioxidants in aging rats. J Nutr Biochem. 1998;9(10):575-81. https://doi. org/10.1016/S0955-2863(98)00052-7

8. Louhelainen $M$, Vahtola $E$, Kaheinen $P$, Leskinen $H$, Merasto S, Kytö V, et al. Effects of levosimendan on cardiac remodeling and cardiomyocyte apoptosis in hypertensive Dahl/Rapp rats. Br J Pharmacol. 2007;150(7):851-61. https://doi.org/10.1038/sj.bjp.0707157

9. Xiao J, She Q, Wang Y, Luo K, Yin Y, Hu R, et al. Effect of allopurinol on cardiomyocyte apoptosis in rats after myocardial infarction. Eur J Heart Fail. 2009;11(1):20-7. https://doi.org/10.1093/eurjhf/hfn003

10. Sunmonu TO, Afolayan AJ. Protective effect of Artemisia afra Jacq. on isoproterenol-induced myocardial injury in Wistar rats. Food Chem Toxicol. 2010;48(7):1969-72. https://doi.org/10.1016/j.fct.2010.04.046

11. Manolis AS, Vassilikos V, Maounis T, Melita-Manolis $H$, Psarros L, Haliasos A, et al. Detection of myocardial injury during radiofrequency catheter ablation by measuring serum cardiac troponin I levels: procedural correlates. J Am Coll Cardiol. 1999;34(4):1099-105. https://doi. org/10.1016/S0735-1097(99)00330-7

12. Zeller L, Novack V, Barski L, Jotkowitz A, Almog Y. Exertional heatstroke: clinical characteristics, diagnostic and therapeutic considerations. Eur J Intern Med. 2011;22(3):296-9. https://doi.org/10.1016/j. ejim.2010.12.013

13. Hernández-Rodríguez J, Segarra M, Vilardell C, Sánchez M, García-Martínez A, Esteban MJ, et al. Tissue production of pro-inflammatory cytokines (IL-1 $\beta$, TNF $\alpha$ and IL-6) correlates with the intensity of the systemic inflammatory response and with corticosteroid requirements in giantcell arteritis. Rheumatology. 2004;43(3):294-301. https:// doi.org/10.1093/rheumatology/keh058

14. Yu M, Wen N, Wenzhong Z, Yuanchang X, Xiaoming D, Yongjin L. Effect of repeated ischaemic preconditioning on TLR4 and proinflammatory cytokines TNF- $\alpha$ and IL-1 $\beta$ in myocardial ischaemia-reperfusion injury in a rat model. Arch Med Sci. 2010;6(6):843-7. https://doi.org/10.5114/aoms.2010.19289

15. Griendling KK, Alexander RW. Oxidative stress and cardiovascular disease. Circulation. 1997;96(10):3264-5.

16. Wang R, Zhang J-Y, Zhang M, Zhai M-G, Di S-Y, Han Q-H, et al. Curcumin attenuates IR-induced myocardial injury by activating SIRT3. Eur Rev Med Pharmacol Sci. 2018;22(4):115060. https://doi.org/10.26355/eurrev_201802_14404

17. Tao Z, Hu F-Q, Li C-F, Zhang T, Cao B-Z, Cui L-Q. Effect of ulinastatin, a human urinary protease inhibitor, on heatstroke-induced apoptosis and inflammatory responses in rats. Exp Ther Med. 2017;13(1):335-41. https://doi.org/10.3892/etm.2016.3926

18. Faleiro L, Kobayashi R, Fearnhead H, Lazebnik Y. Multiple species of CPP32 and Mch2 are the major active caspases present in apoptotic cells. EMBO J. 1997;16(9):2271-81. https://doi.org/10.1093/emboj/16.9.2271

19. Kim Y-M, Talanian RV, Billiar TR. Nitric Oxide Inhibits Apoptosis by Preventing Increases in Caspase-3-like Activity via Two Distinct Mechanisms. J Biol Chem. 1997;272(49):31138-48. https://doi.org/10.1074/jbc.272.49.31138 


\section{Correspondence:}

\section{Qing Song}

Department of Critical Care Medicine, Chinese PLA General Hospital, PLA Medical College 28 Fuxing Road, Haidian District

Beijing 100853 China

Phone: +86-10-66939359

songqingbj@163.com

Received: Aug 12, 2020

Review: Oct 15, 2020

Accepted: Nov 11, 2020
Conflict of interest: none

Financial sources: none

This is an Open Access article distributed under the terms of the Creative Commons Attribution License, which permits unrestricted use, distribution, and reproduction in any medium, provided the original work is properly cited.

${ }^{1}$ Research performed at Laboratory, Chinese PLA General Hospital, PLA Medical College, Beijing, China. 